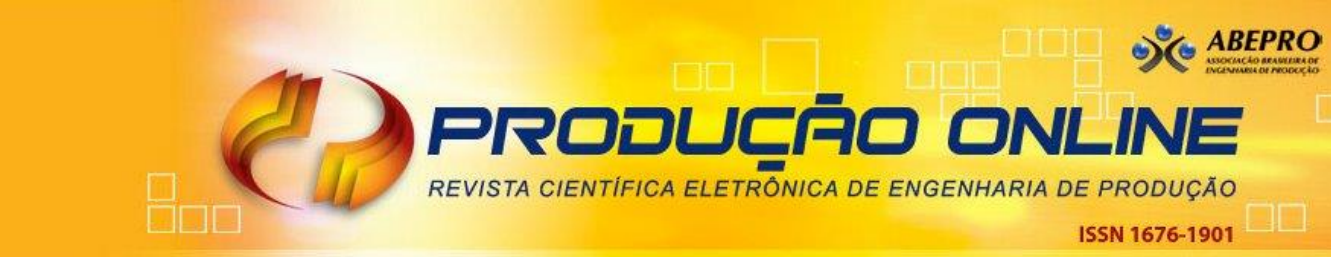

\title{
TÉCNICAS E FERRAMENTAS DE PLANEJAMENTO BASEADAS NA CONSTRUÇÃO ENXUTA E APLICÁVEIS A EMPRESAS DA CONSTRUÇÃO CIVIL: ANÁLISE BIBLIOMÉTRICA
}

\section{TECHNIQUES AND TOOLS OF PLANNING BASED ON THE LEAN CONSTRUCTION AND APPLICABLE TO CONSTRUCTION COMPANIES: BIBLIOMETRIC ANALYSIS}

\author{
Rogério Royer ${ }^{\star}$ E-mail: rogroyer@ufrgs.br \\ Ariane Ferreira Porto Rosa* E-mail: afprosa61@gmail.com \\ Michele Soares Netto* E-mail: michelenetto@live.com \\ *Universidade Federal de Pelotas (UFPel), Pelotas, RS
}

Resumo: $O$ setor da construção civil tem atividades complexas que inclui diversos profissionais, materiais e equipamentos para atingir o empreendimento desejado. A aplicação dos princípios da Construção Enxuta junto com o planejamento em empresas da construção civil, pode significar uma mudança oportuna no processo, contribuindo para que as empresas se firmem no mercado, lucrem e conquistem vantagens competitivas no cenário atual. $O$ presente trabalho realiza uma pesquisa bibliográfica sobre os conceitos de Produção Enxuta, Construção Enxuta e Planejamento e Controle da Produção. Após a pesquisa bibliográfica, realizou-se uma análise bibliométrica, contendo o estudo e análise de publicações recentes do tema proposto, mostrando as técnicas e ferramentas de planejamento utilizadas, buscando a melhoria contínua, redução de custos e prazos das obras.

Palavras-chave: Construção Enxuta. Planejamento. Construção. Análise Bibliométrica.

Abstract: The construction sector has complex activities that include various professionals, materials and equipment to achieve the desired enterprise. The application of the Lean Construction principles together with planning in construction companies, can mean a timely change in the process, helping companies to gain market strength, profit and gain competitive advantage in the current scenario. The present work carries out a bibliographical research on the concepts of Lean Production, Lean Construction and Production Planning and Control. After the bibliographic research, a bibliometric analysis will be carried out, containing the study and analysis of recent publications of the proposed theme, showing the techniques and tools of planning used, seeking continuous improvement, cost reduction and deadlines of the works.

Keywords: Lean Construction. Planning. Construction. Bibliometric Analysis.

\section{INTRODUÇÃO}

Poucas empresas de construção civil operam com alguma técnica que efetue um planejamento detalhado da obra antes de sua execução. Muitas obras ainda são executadas baseadas na experiência dos profissionais envolvidos, os mesmos não se preocupam com uma análise detalhada que se refira às especificações da obra, o

Revista Produção Online. Florianópolis, SC, v.20, n. 3, p. 811-836 2020. 
que não garante que o prazo seja cumprido e nem que o quantitativo do material esteja correto, pois o projeto é controlado usando sistemas informais feitos pelos mestres de obra ou empreiteiros, o que varia muito de um profissional para outro.

Estes procedimentos informais podem gerar aumento do custo inicialmente previsto para obra devido as incertezas quanto aos prazos e materiais envolvidos. Quando a empresa observa que a obra não terminará no prazo estipulado, usualmente tentará reverter a situação aumentando o número de funcionários. $A$ falta de controle na compra e uso dos materiais previamente orçados pode prejudicar o andamento da obra gerando escassez ou desperdício dos mesmos.

Segundo Kotler (2000), o setor da construção civil vem experimentando mudanças com a modificação do perfil dos seus clientes. Os clientes têm exigido produtos de qualidade, preço competitivo e com prazos menores de entrega. A indústria da construção civil tem tentado se adaptar à essas novas exigências de mercado, adotando técnicas de gerenciamento e de produção com o objetivo de otimizar seus processos e produzir produtos cada vez melhores e mais baratos.

É notável que a incerteza nos prazos de execução e na utilização dos materiais em uma obra são as principais fontes de perdas na construção. Logo, é fundamental que cada empresa busque determinar estratégias de gerenciamento que garantam atingir com eficiência o objetivo final, ou seja, a obra esperada (ARAÚJO; MEIRA, 1997).

No Planejamento e Controle da Produção (PCP) tomam-se decisões e são determinadas metas para que os objetivos sejam alcançados, segundo Bernardes (2001). Para atingir o sucesso de qualquer empresa é preciso ter certeza e controle das ações, tornando o planejamento essencial na redução dos custos e dos desperdícios, no cumprimento dos prazos e na obtenção de um padrão de qualidade adequado para o cliente. Assim, torna-se essencial a utilização de métodos de planejamento e controle que permitam um gerenciamento da execução do projeto da obra com coleta informações e controle dos serviços a serem executados na sequência de execução.

A aplicação dos princípios da Construção Enxuta junto com o planejamento em empresas da construção civil pode significar uma mudança oportuna no 
processo, contribuindo para que as empresas se firmem no mercado, lucrem e conquistem vantagens competitivas no cenário atual.

A motivação deste trabalho originou-se na possibilidade de resultados que 0 planejamento e controle da produção podem oferecer, buscando melhorar a confiabilidade e a previsibilidade da execução das atividades na execução de obras de construção civil. O trabalho foi desenvolvido através de uma pesquisa bibliográfica e análise bibliométrica contendo o estudo e análise das publicações recentes do tema proposto, relativo aos últimos 10 anos (2008-2018), para melhor entender a relevância, importância e sua influência na busca da melhoria contínua dos processos na construção civil.

\section{REFERENCIAL TEÓRICO}

$\mathrm{Na}$ presente seção deste trabalho são apresentados os conceitos de Produção Enxuta, Construção Enxuta e Planejamento e Controle da Produção, ilustrando algumas técnicas e ferramentas de planejamento utilizadas no setor da construção civil.

\subsection{Produção Enxuta}

Um sistema produtivo pode ser entendido como um conjunto de processos que proporcionam a obtenção de um dado produto final. Estes processos têm como objetivo produzir um determinado produto ou serviço, que agregue valor para os

clientes e, consequentemente, para a empresa em si, tanto em nível macro quanto micro ambiental.

Gaither e Frazier (2001) e Martins e Laugeni (2005), ressaltam a importância de se entender a produção como um sistema inteiro e interdependente, o qual envolve entrada de insumos, transformação, saída de produtos e controle de resultados para manter a melhoria contínua do processo.

A Produção Enxuta (Lean Manufacturing) também conhecido como Sistema Toyota de Produção surgiu na Toyota Motor Company, no Japão em meados da 
década de 1950 no período pós Segundo Guerra Mundial, foi aplicado pelo Engenheiro Taiichi Ohno (GREEF et al., 2012).

O conceito Produção Enxuta se disseminou internacionalmente por suas características e várias são as definições empregadas. Segundo Rago (2003), a Produção Enxuta apresenta exuberância de processos flexíveis, o que permite a produção ao menor custo, de modo a eliminar as perdas. Já para Ohno (1997) visa também em atender as expectativas dos clientes no menor tempo possível e com extrema qualidade. A ideia básica é produzir apenas o necessário, no momento necessário e na quantidade requerida.

George (2004) define o conceito Produção Enxuta como um conjunto de princípios, com o objetivo de aumentar a velocidade de todos os processos da empresa. De forma sintetizada, consiste na implementação de um conjunto de técnicas e ferramentas focadas na otimização de processos e na redução de desperdícios. Este conjunto de técnicas e ferramentas precisa ser cuidadosamente aplicado de modo a atender as necessidades da empresa.

Para se alcançar um estado de produção enxuta, é necessário identificar as atividades envolvidas no processo produtivo classificando-as naquelas que agregam ou não valor, de modo a eliminar os desperdícios. Segundo Shingo (1996), todas as atividades que não agregam valor, são categorizadas como perdas.

A Produção Enxuta parte da pressuposição da existência de sete tipos de desperdícios em uma empresa, sendo uma finalidade sua tentar eliminar custos que não geram valor para a empresa (OHNO, 1997). No Quadro 1, são descritas as sete perdas no processo produtivo segundo Shingo (1996) e Ohno (1997).

A Produção Enxuta, além do esforço para eliminação dos desperdícios, caracteriza-se também pela não aceitação da situação vigente ou ainda de padrões arbitrários de desempenho (CORRÊA et al., 1996). As metas propostas na produção enxuta para solução dos vários problemas de produção são: zero defeitos; tempo zero de preparação (set up); estoque zero; movimentação zero; quebra zero; lead time zero; e lote unitário (SHINGO, 1996). 
Quadro 1 - Sete perdas do processo produtivo (continua)

\begin{tabular}{|l|l|}
\hline \multicolumn{1}{|c|}{ Perdas } & \multicolumn{1}{c|}{ CONCEITO } \\
\hline Superprodução & $\begin{array}{l}\text { Relacionada à quantidade, refere-se à produção em excesso, } \\
\text { produzir em quantidades superiores a do volume programado. }\end{array}$ \\
\hline Espera & $\begin{array}{l}\text { Consiste no tempo de ociosidade seja de pessoas, informações ou } \\
\text { peças/materiais, que impossibilitam o início do próximo processo. }\end{array}$ \\
\hline Transporte & $\begin{array}{l}\text { Refere-se ao excesso de movimentos seja de pessoas, } \\
\text { peças/materiais ou informações. }\end{array}$ \\
\hline Processamento & $\begin{array}{l}\text { Baseia-se na utilização equivocada das ferramentas, dos sistemas } \\
\text { e dos procedimentos. São usados de forma inadequada as } \\
\text { máquinas e os equipamentos. }\end{array}$ \\
\hline Estoque & $\begin{array}{l}\text { Refere-se ao armazenamento demasiado seja de matéria prima, } \\
\text { produtos acabados ou semiacabados. Logo, torna-se um } \\
\text { desperdício em termo de espaço e investimento. }\end{array}$ \\
\hline Movimento & $\begin{array}{l}\text { Relacionada à desorganização do layout fabril, resultando em } \\
\text { movimentos desnecessários realizados pelo operador em suas } \\
\text { atividades. }\end{array}$ \\
\hline $\begin{array}{l}\text { Fabricação de } \\
\text { peças e produtos } \\
\text { defeituosos }\end{array}$ & $\begin{array}{l}\text { Relacionada à fabricação de produtos que apresentam } \\
\text { características de qualidade fora do especificado, ou seja, que não } \\
\text { atendem as especificações dos clientes. }\end{array}$ \\
\hline
\end{tabular}

Fonte: Adaptado pelos autores de Shingo (1996) e Ohno (1997).

O modelo de Produção Enxuta possui várias metodologias e técnicas de produção e gestão industrial que são utilizadas atualmente pelas empresas. Algumas dessas surgiram no decorrer das últimas décadas, como por exemplo: JustIn-Time (JIT); Total Quality Management (TQM); Total Productive Maintenance (TPM); e Filosofia Kaizen. Além disso, para Rother e Shook (2012), o Mapeamento de Fluxo de Valor (MFV) surgiu para preencher os objetivos supracitados, enfocando todo o fluxo de produção de um produto ou família de produtos, visando à implantação da Produção Enxuta em todo o fluxo.

Outras técnicas utilizadas na Produção Enxuta são os dispositivos Kanban e Poka-Yoke. O Kanban é um dispositivo sinalizador que autoriza e dá instrução para a produção ou retirada de itens para sistema puxado. Pode ser utilizado para evitar os excessos de produção, de modo a eliminar desperdícios e restabelecer o nível de estoque de acordo com a demanda. Já o Poka-Yoke é um dispositivo à prova de erros ou falhas, é qualquer mecanismo que evite que o erro acorra e torna-se um defeito. Pode ser utilizado para detectar ou corrigir as falhas que podem ocorrer durante o processo de manufatura, antes que seja percebida pelos clientes. 


\subsection{Construção Enxuta}

O crescimento de empresas no setor da construção civil e a competitividade entre elas no mercado atual, faz com que as empresas busquem formas inovadoras de evitar problemas no ambiente construtivo, focando nos métodos produtivos, buscando um melhor desempenho, ganho de produtividade, ganho na qualidade do produto final e reduzindo os desperdícios.

Existem diferenças relevantes entre a indústria de manufatura e da construção civil. O volume de produção é uma das diferenças, na construção civil se produz um único produto, enquanto na manufatura tem grande quantidade. Para que as obras sejam realizadas depende da condição climática e da mão de obra que tem alta rotatividade, são fatores que mostram que a indústria da construção tem um alto grau de incerteza, tornando mais complexa implantar os princípios da Produção Enxuta. Ballard e Howell (2004) caracterizam a Construção Civil como uma indústria que possui um sistema de produção temporário, visando a entregar o produto de forma que os valores sejam maximizados e os desperdícios sejam minimizados.

Koskela (1992) apresentou o modelo para a construção civil chamado de Lean Construction, ou Construção Enxuta, que veio da Produção Enxuta (Lean Production), que é um modelo inovador que define o sistema produtivo envolvendo funcionários, clientes e fornecedores. "A Produção Enxuta expõe conceitos que tem o objetivo de trazer benefícios, tratando-se de eficiência e produtividade colocando em práticas os seus princípios enxutos" (BERNARDES, 2003).

A Construção Enxuta pode ser entendida pela integração entre o produto e o planejamento de resultados, por meio da integração de todos os envolvidos. Sendo uma nova filosofia de produção, muito diferente da produção convencional, pois ela é formada por atividades de conversão e de fluxo, mostrando quais as atividades que agregam ou não valor ao produto. A principal diferença entre as filosofias é o modo de entender os processos. De acordo com Isatto (2000) o modelo convencional tende a modificar a matéria prima em produtos intermediários ou final, sendo denominado modelo de conversão. Partindo da visão da filosofia tradicional, os custos do processo podem ser reduzidos com a diminuição dos custos dos subprocessos (KOSKELA, 1992). 
$\mathrm{Na}$ construção enxuta os custos totais de uma obra, estão junto com os custos das atividades que não agregam valor nenhum no ponto de vista do cliente, portanto, eliminar as atividades que não agregam valor traz um lucro maior para a empresa. A Construção Enxuta divide o processo construtivo entre as etapas de fluxo de materiais e mão de obra, e conversão, conceituando o que ocorre na produção, da escolha de materiais ao produto final. São consideradas atividades de fluxo, as que não agregam valor ao produto final, que são as de espera, de transporte, de processo e de inspeção. A atividade de processo que agrega valor ao produto final, é definida como atividade de conversão.

A construção civil deve pensar, primeiro, nos desejos dos clientes do produto final, evitando a instabilidade, a variação dos processos e os desperdícios da produção. Os processos deverão ser resumidos, diminuindo parte de componentes dos produtos e reduzindo as etapas dos fluxos de materiais e informações, sem prejudicar a produção (KOSKELA, 1994). O Quadro 2 ilustra as diferenças entre a filosofia convencional de produção e a filosofia enxuta.

Quadro 2 - Comparativo entre a filosofia convencional de produção e a filosofia enxuta

\begin{tabular}{|l|l|l|}
\hline \multicolumn{1}{|c|}{ Conceitos } & \multicolumn{1}{|c|}{ Filosofia Convencional } & \multicolumn{1}{c|}{ Filosofia Enxuta } \\
\hline Conceito de produção & $\begin{array}{l}\text { Produção consiste em } \\
\text { conversões de atividades, } \\
\text { todas as atividades agregam } \\
\text { valor . }\end{array}$ & $\begin{array}{l}\text { Produção consiste em } \\
\text { conversão e fluxo: existem } \\
\text { atividades que agregam valor e } \\
\text { que não agregam valor. }\end{array}$ \\
\hline Foco do controle & Custo das atividades & $\begin{array}{l}\text { Custo, tempo e fluxo de valor } \\
\text { Foco de melhorias }\end{array}$ \\
$\begin{array}{l}\text { Aumentar a eficiência pela } \\
\text { implementação de novas } \\
\text { tecnologia. }\end{array}$ & $\begin{array}{l}\text { Eliminação ou supressão das } \\
\text { atividades que não agregam } \\
\text { valor, aumento de eficiência das } \\
\text { atividades que agregam valor } \\
\text { através de melhorias contínuas e } \\
\text { novas tecnologias. }\end{array}$ \\
\hline
\end{tabular}

Fonte: Adaptado pelos autores de Koskela (1994).

Com o objetivo de auxiliar, foi criado um padrão para as empresas implantarem a Construção Enxuta, Koskela (1992) apontou onze princípios fundamentais para a gestão dos processos. Picchi (2003) enfoca que os onze 
princípios de Koskela (1992) foram propostos com base no trabalho de Womack e Jones (1998), que propuseram cinco princípios largamente disseminados e adotados em diversos setores: Valor; Fluxo de Valor, Fluxo, Puxar, Perfeição.

No ano de 2000 os onze esses princípios propostos por Koskela (1992) foram reduzidos a seis, os quais são: redução da quantidade de atividades que não agregam valor ao produto; redução da variabilidade do processo produtivo, visando à padronização; simplificação da execução das atividades através da redução do número de etapas; redução do tempo de espera (lead time); aumento da flexibilidade de saída; aumento da transparência no processo (KOSKELA, 2000).

Bertelsen e Koskela (2004) afirmam haver uma diferença na percepção do cliente entre a Construção Enxuta e a Manufatura Enxuta. Na Manufatura Enxuta é possível determinar os parâmetros de valor do mercado e desenvolver os produtos de acordo com eles. Entretanto, na Construção Enxuta, não há um cliente específico, já que seus produtos têm importância para várias partes. Segundo Bertelsen e Koskela (2004) o cliente pode ser representado por um grande número de interesses, de diferentes perspectivas de tempo.

Alguns trabalhos sobre Construção Enxuta e aplicações foram realizados em âmbito nacional. Leite et al. (2004) apresentaram um estudo de caso com aplicação do sistema kanban no transporte de materiais na construção civil.

Peretti et al. (2013) propuseram um estudo para verificar como são adotadas as ferramentas e os princípios da Construção Enxuta, em construtoras verticais da Região Metropolitana de São Paulo. Realizaram uma pesquisa qualitativa, de natureza exploratória, desenvolvida por meio de estudo de casos múltiplos em três empresas de diferentes portes.

Mariz e Picchi (2014) analisaram como foi aplicada uma célula de produção em um serviço de execução de fachada e avaliaram os resultados obtidos. Para tanto, realizaram um estudo de caso em um fornecedor que executa fachadas para uma grande incorporadora. Foram coletados dados qualitativos (observações in loco e entrevista com funcionários) e quantitativos (dados de prazos e custos fornecidos pela construtora) para posterior análise dos mesmos, antes e pós implementação da célula de fachada. 
Cândido et al. (2016) apresentaram uma aplicação da Gerenciamento do Valor Agregado (Earned Value Management, EVM) ou, que é uma técnica de medição e controle de projetos baseada na medição física, financeira e de tempo que proporciona indicadores de avanço real, variações de desempenho e previsões para conclusão do projeto. Através de um estudo de caso único, exploratório e descritivo, os autores analisaram o uso da técnica do EVM em um projeto de construção sob a ótica da Construção Enxuta. O estudo realizado pode confirmar alguns problemas levantados em outros trabalhos, bem como expandi-los, proporcionando uma visão mais holística sobre a aplicabilidade dessa técnica na construção civil, especialmente em obras cuja construção enxuta é aplicada.

\subsection{Planejamento e Controle da Produção}

O Planejamento e Controle da Produção (PCP) envolve atividades de gestão a serem introduzidas para realizar a produção de um produto. Esta gestão é formada pelas funções mais simples de planejamento e controle, onde no planejamento se estabelece metas e a sequência que se deseja para atingi-la, enquanto que o controle tem a função de fazer com que esse fato se aproxime do que foi planejado.

O PCP é responsável por fornecer as informações necessárias para a gestão no fluxo de materiais na produção, para que seja eficiente, e eficaz no uso dos recursos.

Segundo Tubino (2007) as atividades do PCP organizam e utilizam os recursos produtivos, visando atender da melhor forma, os planos estabelecidos nos três níveis hierárquicos da organização, que são: planejamento estratégico (longo prazo), planejamento tático (médio prazo) e planejamento operacional (curto prazo).

\section{METODOLOGIA}

A metodologia desta pesquisa é a pesquisa bibliográfica baseada na bibliometria. A bibliometria é uma ferramenta muito utilizada ao realizar estudos que envolvam levantamento e análise de produções científicas. Segundo Araújo (2006), é baseada na contagem de artigos científicos, patentes e citações, com o objetivo de descrever aspectos da literatura através de análise quantitativa da produção escrita.

Revista Produção Online. Florianópolis, SC, v.20, n. 3, p. 811-836 2020. 
Segundo Moretti e Campanário (2009) a pesquisa bibliométrica busca identificar a produtividade de autores em certo tema, e apresentar os periódicos mais relevantes para a publicação em dada área do conhecimento. Para Moraes (2013) a pesquisa bibliométrica é um estudo para as produções científicas, é a base de sustentação para produzir novos trabalhos.

Com o intuito de encontrar trabalhos na área da construção civil, relacionadas a Construção Enxuta e o Planejamento e Controle da Produção, inicialmente foi feita uma pesquisa bibliográfica, em artigos disponíveis na mídia digital, livros, para basear e esclarecer o tema proposto. As fontes mencionadas anteriormente, foram por pesquisa bibliográfica e análise bibliométrica de publicações recentes, de 2008 a 2018.

Figura 1 - Etapas para análise bibliométrica

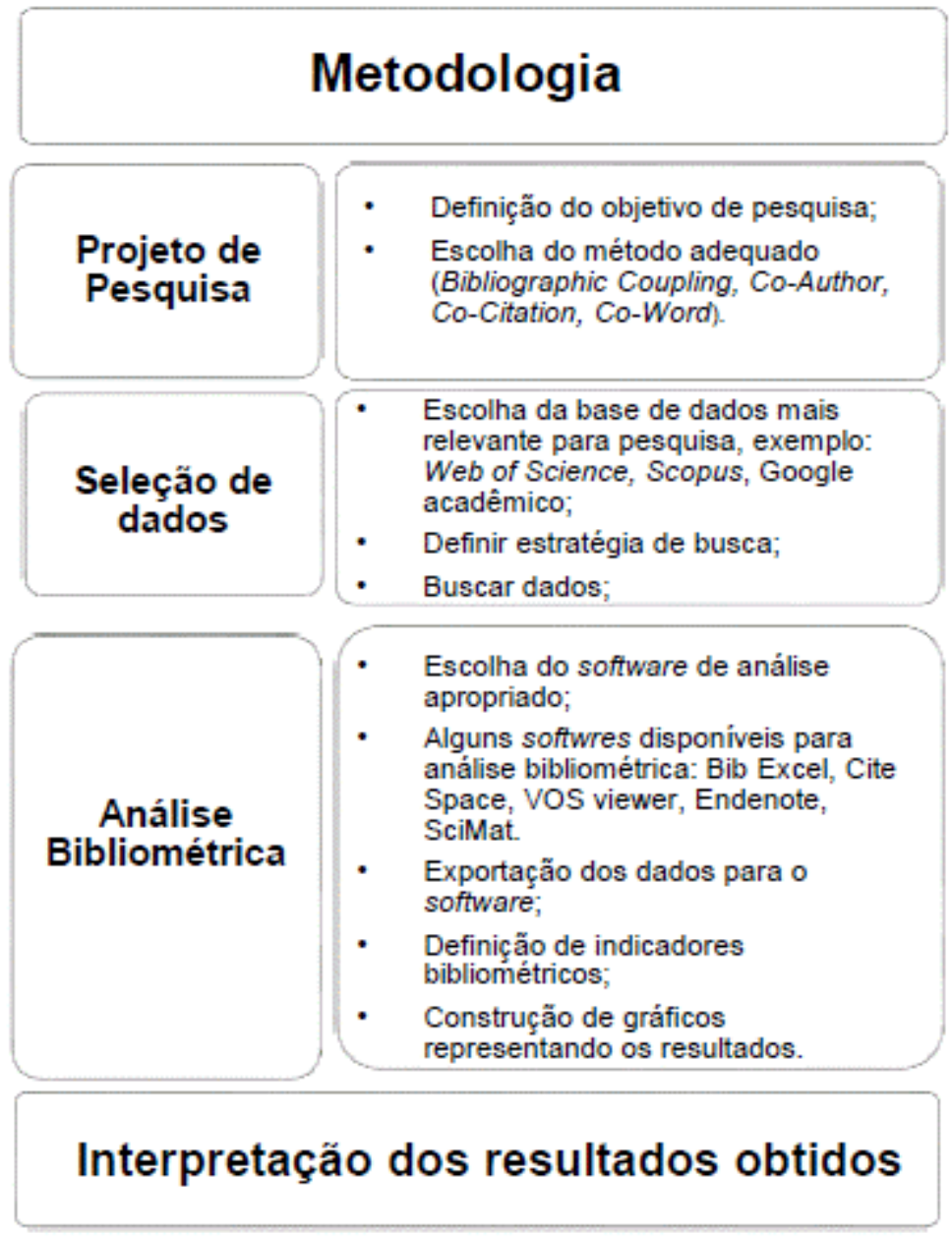

Fonte: Autores. 
A Figura 1 descreve os procedimentos necessários para que seja desenvolvida uma análise bibliométrica, de forma genérica. Na etapa projeto de pesquisa devem ser definidos os objetivos da pesquisa e o método apropriado para que estes objetivos sejam alcançados. Durante a etapa de seleção de dados a bases de dados utilizada para coleta dos artigos é definida, após deve-se definir a estratégia de busca para coleta de dados e em seguida a realização da busca propriamente dita.

A etapa de análise bibliométrica deve se concentrar na definição do software a ser utilizado para análise dos dados, na exportação dos dados para o software, na definição de indicadores bibliométricos para avaliação dos dados sob análise (que pode variar em cada software). Durante a análise bibliométrica gráficos com a representação dos dados são construídos para posterior interpretação e análise dos resultados obtidos.

\subsection{Procedimentos de Coleta de Dados}

Para a pesquisa de dados foi utilizada a plataforma do Portal Periódicos Capes. Foi definida a base de dados Web of Science (WOS), para buscar os termos de pesquisa. A WOS é uma base que disponibiliza acesso a mais de 9.200 títulos de periódicos, possibilita identificar artigos de periódicos em diversas áreas do conhecimento, pode ser utilizada para uma pesquisa de alta qualidade, processando os resultados de uma busca e salvando-os.

Com o objetivo de encontrar técnicas e ferramentas de planejamento na área da construção civil, baseadas na construção enxuta, foram utilizadas as palavraschave: construção enxuta, produção enxuta e construção, porém com o objetivo de encontrar o maior número de publicações, a busca foi feita utilizando as palavraschave em inglês "Lean Construction", "Lean Production and Construction". Foram analisados os termos no período de 2008 a 2018, filtrando a busca nos campos resumo, título e palavras-chave. 


\subsection{Procedimentos de Análise de Dados}

Para o estudo bibliométrico é preciso usar um software. Após as duas pesquisas na WOS, com os termos "Lean construction" e "Lean production and Construction", foi gerado um arquivo, exportado para o software escolhido, VOSviewer, com uma análise de co-ocorrência de palavras, criando mapas baseados nos dados bibliográficos. Para cada termo foi definido o número mínimo de ocorrências de cada palavra-chave.

\section{RESULTADOS}

Os resultados da análise bibliométrica de cada termo, efetuada pelo software VOSviewer, gera três tipos de visualizações: de rede, de sobreposição e de densidade.

\subsection{Construção Enxuta}

A pesquisa com o termo "Lean Construction" resultou em 252 artigos encontrados na WOS. Ao exportar esses dados para o VOSviewer, encontramos 860 palavras-chave que se repetem. Após definir em 10 como ocorrência mínima de cada palavra-chave, encontramos 17 palavras-chave, que são chamadas de itens, que se repetem pelo menos 10 vezes.

$\mathrm{Na}$ visualização de rede os itens são representados por círculos, o tamanho do círculo é determinado pela quantidade de ocorrência. A cor de um item é determinada pelo cluster ao qual o item pertence, as palavras-chave do cluster 1 são representadas pela cor vermelha, as do cluster 2 são representadas pela cor verde $e$ as do cluster 3 são representadas pela cor azul. As linhas entre os itens representam as ligações, a distância entre dois itens indica a proximidade entre eles. $\mathrm{Na}$ Figura 2 pode ser observada a composição de cada cluster, que representam os grupos de palavras-chaves com maior afinidade entre si. 
Figura 2 - Visualização de rede do termo "Lean Construction"

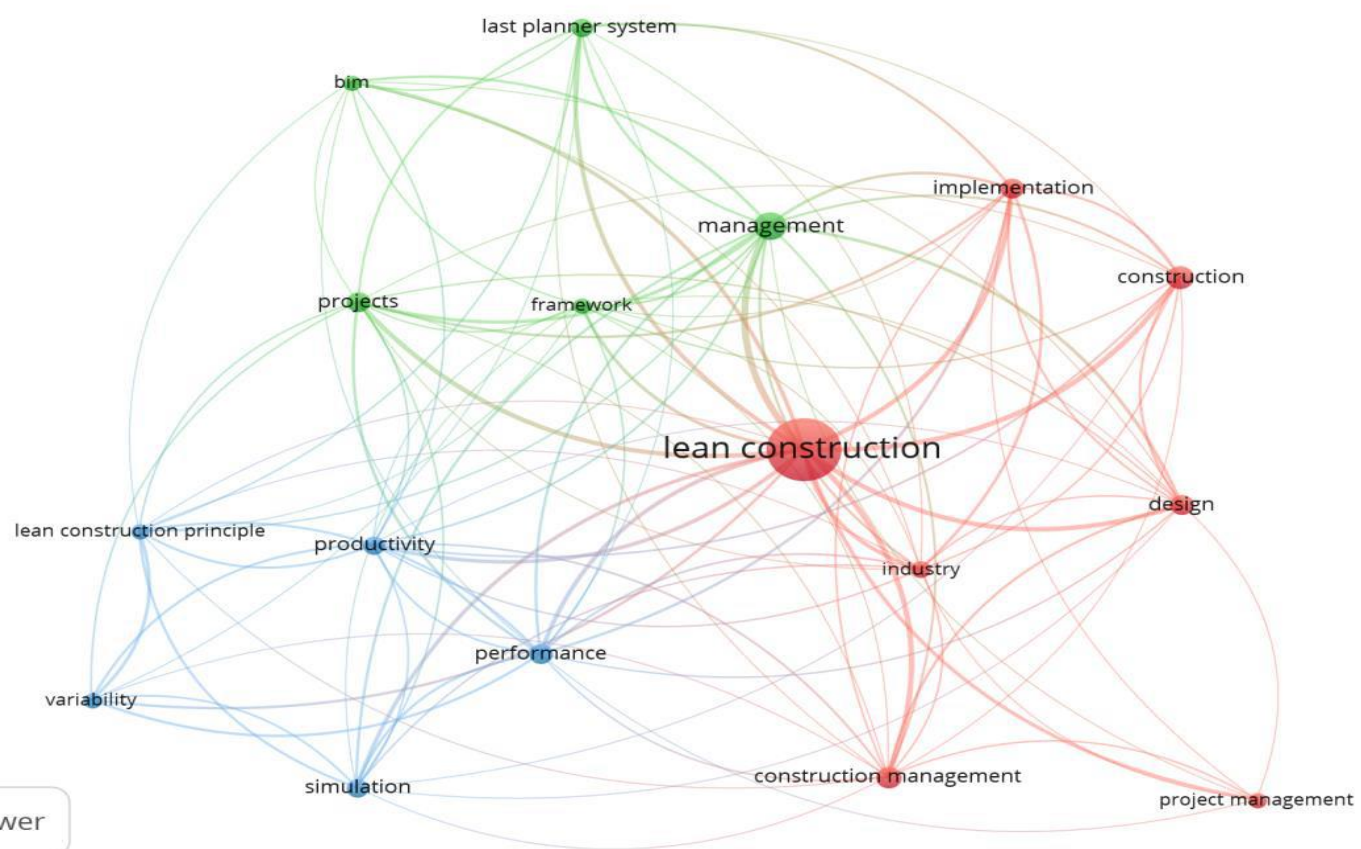

S vosviewer

Fonte: Autores através do software VOSviewer

Figura 3 - Visualização de sobreposição do termo "Lean Construction"

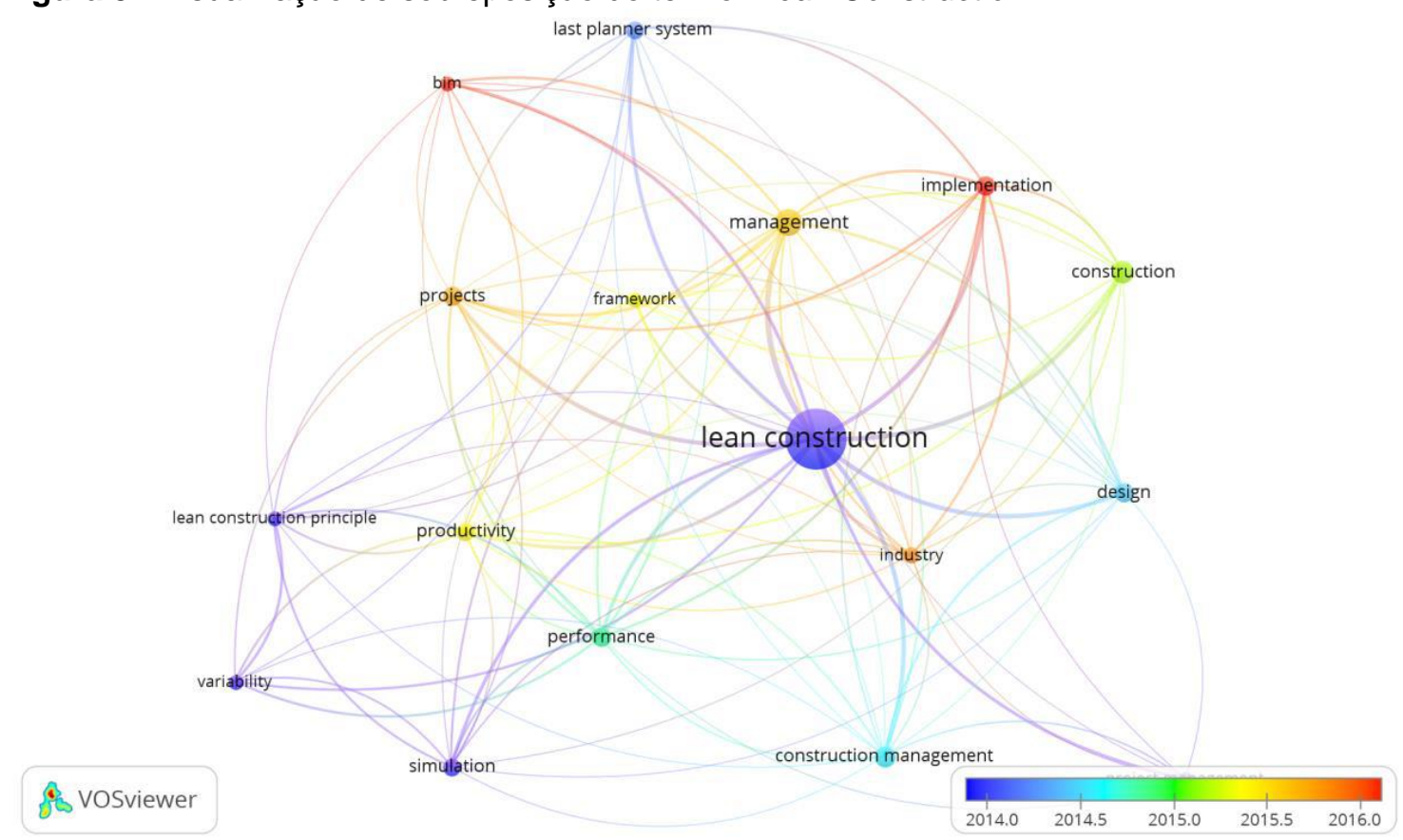

Fonte: Autores através do software VOSviewer

A visualização de sobreposição é semelhante à visualização de rede, porém o círculo tem a cor do ano médio de publicação de cada item. A barra de cores, no canto inferior direito da Figura 3, a seguir, indica o ano das publicações que são

Revista Produção Online. Florianópolis, SC, v.20, n. 3, p. 811-836 2020. 
mapeadas por cada cor. As cores variam de azul (publicações mais antigas) a vermelho (publicações mais recentes), assim identificamos a existência das palavras-chave nos artigos ao passar dos anos, mostrando que maior parte delas estão entre os anos de 2014 e 2016.

A visualização de densidade é ilustrada na Figura 4. Sendo semelhante as outras visualizações, os itens são representados por pontos, cada ponto tem uma cor que indica a densidade dos itens nesse ponto. Por padrão, as cores variam de azul para verde para amarelo para vermelho.

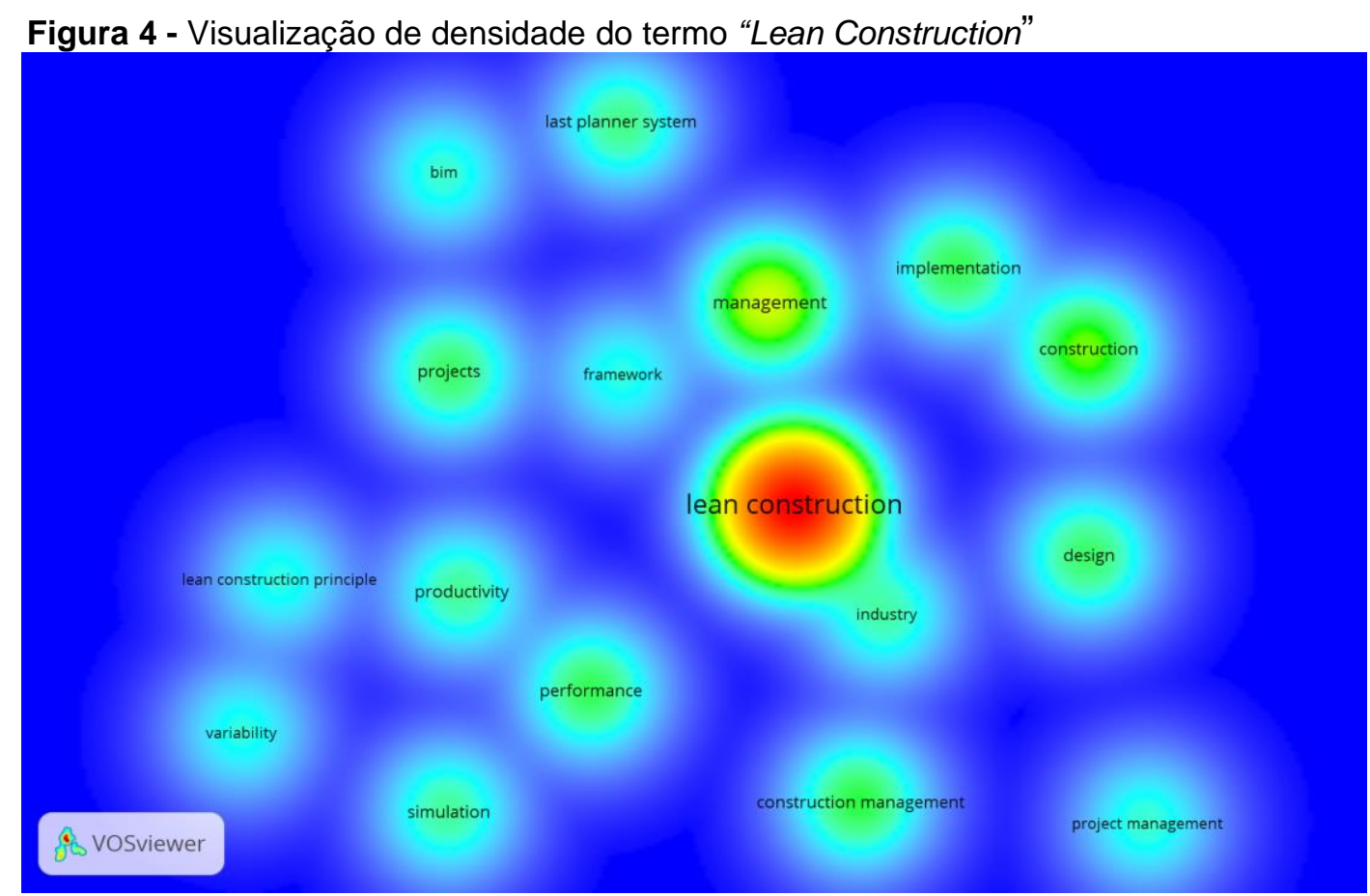

Fonte: Autores através do software VOSviewer

Pode ser observado na Figura 4 que quanto maior o número de itens na vizinhança de um ponto e quanto maiores os pesos dos itens vizinhos, mais próxima a cor do ponto é vermelha. Ao contrário, quanto menor o número de itens na vizinhança de um ponto e menores os pesos dos itens vizinhos, mais próxima a cor do ponto é a azul.

A Tabela 1 contém os dados das três visualizações do termo "Lean Construction". 
Tabela 1 - Dados considerados durante a análise bibliométrica para o termo "Lean Construction"

\begin{tabular}{|c|c|c|c|c|c|}
\hline Cluster & Item & Ocorrência & Ligação & $\begin{array}{l}\text { Força } \\
\text { total da } \\
\text { ligação }\end{array}$ & $\begin{array}{c}\text { Ano médio } \\
\text { da } \\
\text { publicação }\end{array}$ \\
\hline \multirow{7}{*}{$\begin{array}{l}\text { Cluster } 1 \text { - } \\
7 \text { itens }\end{array}$} & Construção enxuta (lean construction) & 167 & 16 & 179 & 2014,03 \\
\hline & Construção (construction) & 24 & 11 & 39 & 2015,17 \\
\hline & Gestão da construção (construction management) & 19 & 15 & 40 & 2014,58 \\
\hline & Implementação (implementation) & 18 & 11 & 50 & 2016,39 \\
\hline & Design & 17 & 13 & 44 & 2014,47 \\
\hline & Indústria (industry) & 13 & 15 & 38 & 2015,77 \\
\hline & Gerenciamento de projeto (project management) & 11 & 7 & 15 & 2013,73 \\
\hline \multirow{5}{*}{$\begin{array}{c}\text { Cluster } 2 \text { - } \\
5 \text { itens }\end{array}$} & Gestão (management) & 33 & 15 & 83 & 2015,55 \\
\hline & Projetos (projects) & 17 & 15 & 51 & 2015,65 \\
\hline & Last planner system (LPS) & 15 & 11 & 31 & 2014,27 \\
\hline & Building Information Modeling (BIM) & 11 & 10 & 25 & 2016,91 \\
\hline & Estrutura (framework) & 10 & 13 & 26 & 2015,30 \\
\hline \multirow{5}{*}{$\begin{array}{l}\text { Cluster } 3 \text { - } \\
5 \text { itens }\end{array}$} & Desempenho (perfomance) & 18 & 15 & 53 & 2014,83 \\
\hline & Produtividade (productivity) & 14 & 13 & 40 & 2015,36 \\
\hline & Simulação (simulation) & 14 & 12 & 34 & 2014,00 \\
\hline & $\begin{array}{l}\text { Princípio da construção enxuta (lean construction } \\
\text { principle) }\end{array}$ & 10 & 12 & 29 & 2013,30 \\
\hline & Variabilidade (variability) & 10 & 8 & 27 & 2013,60 \\
\hline
\end{tabular}

Fonte: Autores

\subsection{Produção Enxuta e Construção}

Usando os termos "Lean Production" and "Construction", foram encontrados 197 artigos na WOS, porém, 82 dos artigos eram os mesmos que encontramos ao usar o termo "Lean Construction", para atingir o objetivo da pesquisa com maior precisão, excluímos os artigos repetidos, então a pesquisa foi baseada em 105 artigos. Ao exportar os dados para o VOSviewer, encontramos 544 palavras-chave que se repetem. Definimos a ocorrência mínimo em 6. Encontramos 19 palavraschave, ou itens, que se repetem pelo menos 6 vezes.

A visualização de rede os itens são representados por 19 círculos e três clusters. As palavras-chave do cluster 1 são representadas pela cor vermelha, as do cluster 2 são representadas pela cor verde e as do cluster 3 são representadas pela cor azul. Na Figura 5 pode ser observada a composição de cada cluster, que representam os grupos de palavras-chaves com maior afinidade entre si. 
Figura 5 - Visualização de rede do termo "Lean Production" and "Construction"

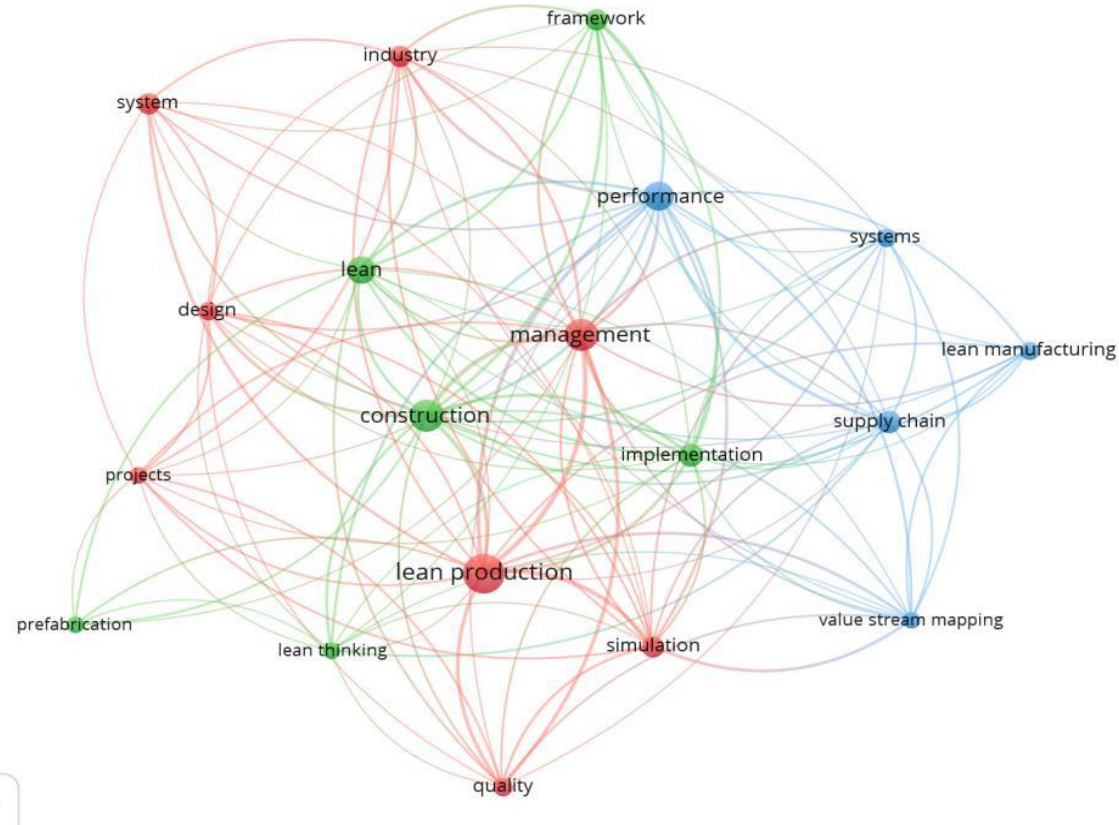

B VOSviewer

Fonte: Autores através do software VOSviewer

A visualização de sobreposição é ilustrada na Figura 6, abaixo, mostrando que a maioria das publicações estão entre 2014 e 2016. As cores dos círculos variam de azul (publicações mais antigas) a vermelho (publicações mais recentes).

Figura 6 - Visualização de sobreposição do termo "Lean Production" and "Construction"

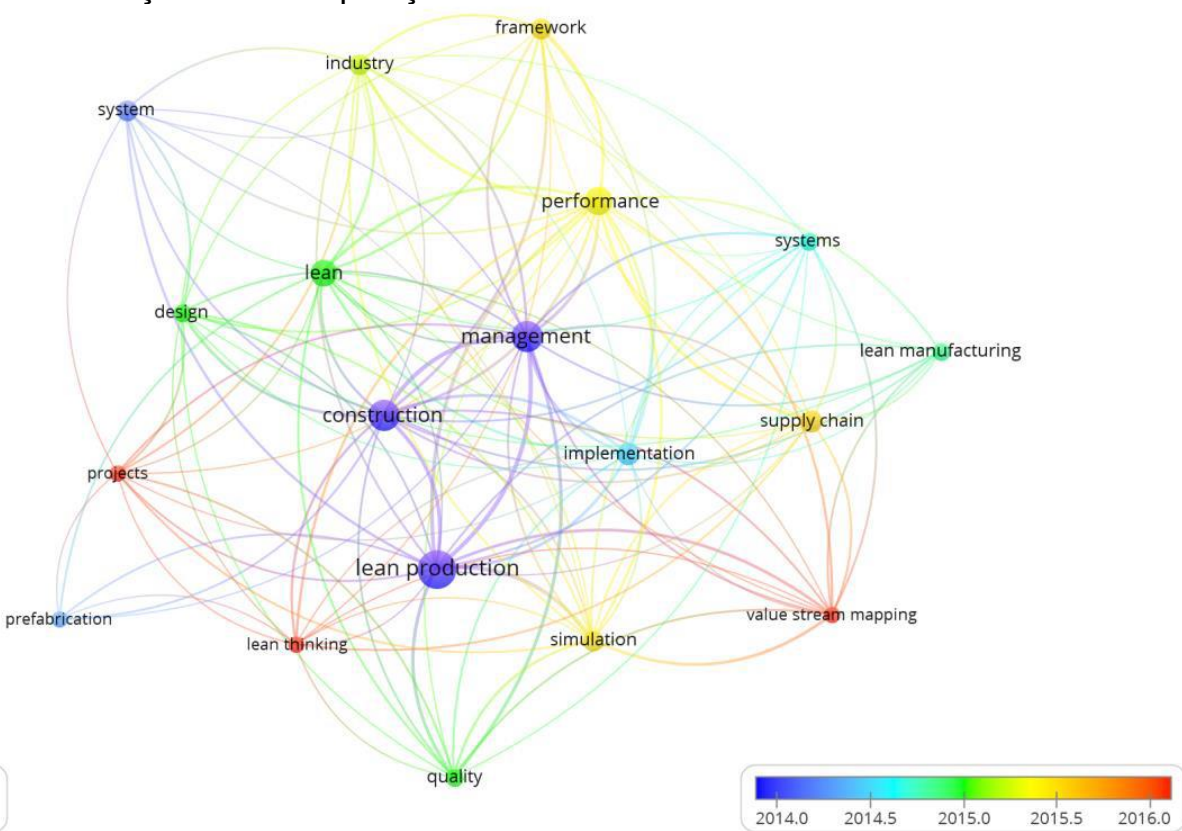

Fonte: Autores através do software VOSviewer

Revista Produção Online. Florianópolis, SC, v.20, n. 3, p. 811-836 2020. 
A visualização de densidade é ilustrada na Figura 7. Sendo semelhante as demais, os 19 itens são representados por pontos, cada ponto tem uma cor, cada cor indica a densidade dos itens nesse ponto. As cores variam de azul para verde para amarelo para vermelho. Quanto maior o número de itens na vizinhança de um ponto e quanto maiores os pesos dos itens vizinhos, mais próxima a cor do ponto é vermelha, e quanto menor o número de itens na vizinhança de um ponto e menores os pesos dos itens vizinhos, mais próxima a cor do ponto é a azul.

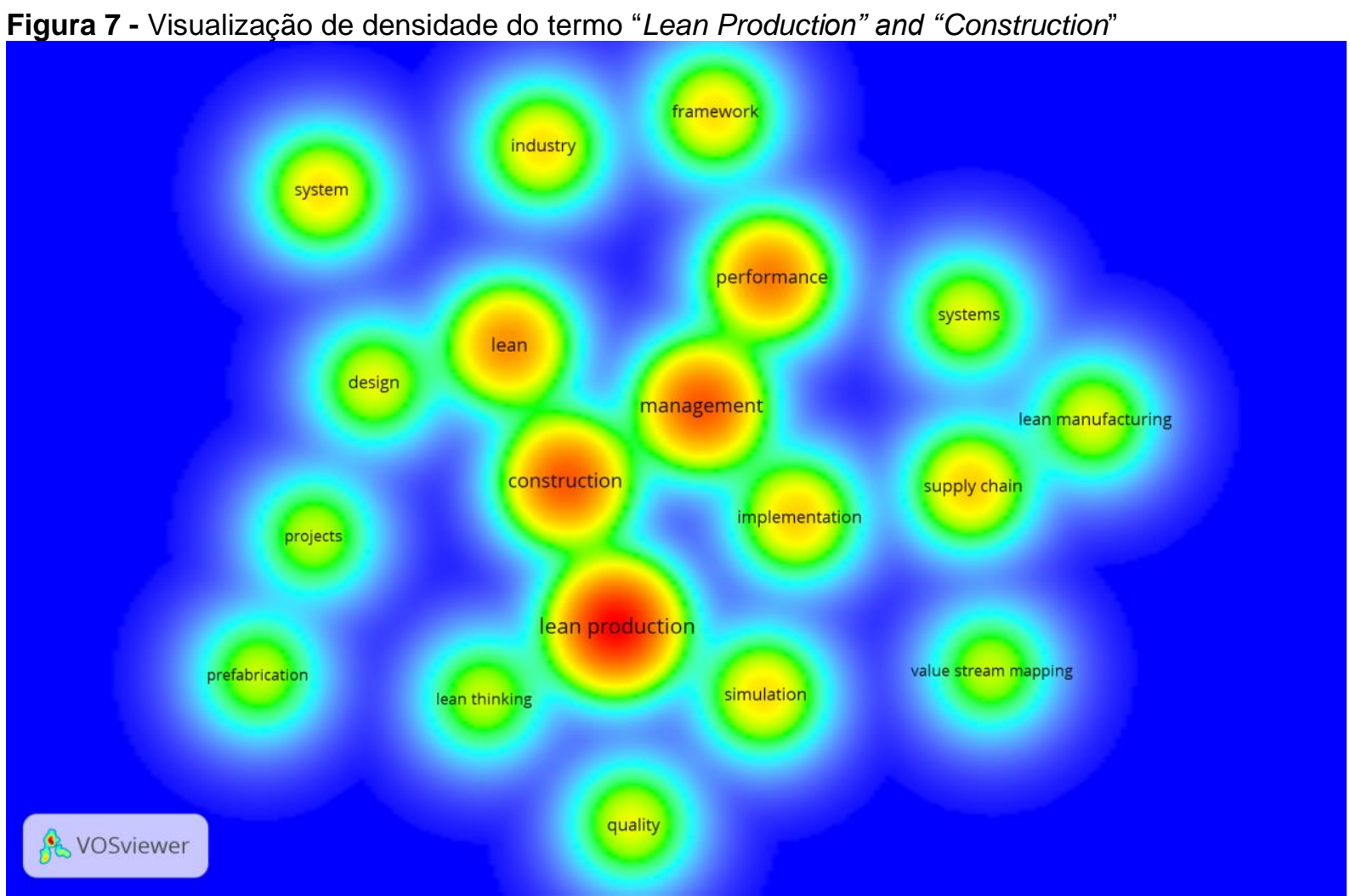

Fonte: Autores através do software VOSviewer

A Tabela 2, a seguir, contém os dados de cada uma das três visualizações do termo "Lean Production" and "Construction", geradas pelo software VOSviewer. 
Tabela 2 - Dados considerados durante a análise bibliométrica para o termo "Lean Production" and "Construction"

\begin{tabular}{|c|c|c|c|c|c|}
\hline Cluster & Item & Ocorrência & Ligação & $\begin{array}{c}\text { Força } \\
\text { total da } \\
\text { ligação }\end{array}$ & $\begin{array}{c}\text { Ano médio } \\
\text { de } \\
\text { publicação }\end{array}$ \\
\hline \multirow{8}{*}{$\begin{array}{c}\text { Cluster } 1 \text { - } \\
8 \text { itens }\end{array}$} & Produção enxuta (lean production) & 32 & 17 & 58 & 2013,66 \\
\hline & Gestão (management) & 21 & 17 & 54 & 2013,76 \\
\hline & Simulação (simulation) & 9 & 15 & 36 & 2015,44 \\
\hline & Indústria (industry) & 9 & 14 & 28 & 2015,22 \\
\hline & Sistema (system) & 9 & 10 & 16 & 2014,22 \\
\hline & Qualidade (quality) & 7 & 12 & 27 & 2015,00 \\
\hline & Design & 7 & 13 & 22 & 2015,00 \\
\hline & Projetos (projects) & 6 & 12 & 18 & 2016,33 \\
\hline \multirow{6}{*}{$\begin{array}{c}\text { Cluster } 2 \text { - } \\
6 \text { itens }\end{array}$} & Construção (construction) & 21 & 17 & 53 & 2013,90 \\
\hline & Enxuto (lean) & 15 & 15 & 29 & 2015,00 \\
\hline & Implementação (implementation) & 10 & 16 & 32 & 2014,50 \\
\hline & Estrutura (framework) & 9 & 12 & 25 & 2015,44 \\
\hline & Pensamento enxuto (lean thinking) & 6 & 12 & 17 & 2016,83 \\
\hline & Pré-fabricação (prefabrication) & 6 & 6 & 9 & 2014,33 \\
\hline \multirow{5}{*}{$\begin{array}{c}\text { Cluster } 3 \text { - } \\
5 \text { itens }\end{array}$} & Desempenho (perfomance) & 17 & 17 & 55 & 2015,35 \\
\hline & Cadeia de suprimentos (supply chain) & 10 & 13 & 24 & 2015,50 \\
\hline & Sistemas (systems) & 7 & 12 & 19 & 2014,71 \\
\hline & Manufatura enxuta (lean manufacturing) & 7 & 9 & 15 & 2014,86 \\
\hline & $\begin{array}{l}\text { Mapeamento do Fluxo de Valor (value stream } \\
\text { mapping) }\end{array}$ & 6 & 13 & 27 & 2016,00 \\
\hline
\end{tabular}

Fonte: Autores

\section{CONSIDERAÇÕES}

Os resultados da análise bibliométrica realizada com publicações que tinham os termos "Lean Construction", e "Lean Production" and "Construction", no resumo, no título e/ou nas palavras-chave, no período de 2008 a 2018, foram feitos analisando os dados obtidos, para que estivessem de acordo com o assunto do presente trabalho.

Para que a construção da análise bibliométrica seja efetiva alguns itens, tais como a escolha adequada da base de dados e a busca dos itens, devem ser observados com atenção. É importante escolher a base adequada que atenda as expectativas da pesquisa almejada e seja correspondente a área de conhecimento da pesquisa.

Neste caso foi escolhida uma base de dados multidisciplinar, pois buscamos entender a evolução dos termos pesquisados em diversas áreas, para que o termo 
não fosse limitado a apenas uma área ou campo de atuação, visto que as ferramentas estatísticas apresentam um vasto campo de aplicação.

Contudo a base escolhida, WOS, indexa apenas os periódicos mais citados em suas respectivas áreas, por isso o número de publicações sobre cada termo não foi tão grande. Além disso, os filtros e palavras-chaves utilizados para a busca dos termos apresentam grande impacto na análise. Por isso é necessário observar os resultados das buscas para verificar se estes não se distanciam do objeto da pesquisa e se não é necessário a troca ou alteração dos termos pesquisados.

Como os filtros da base de dados WOS não são tão robustos quanto os de outras bases existentes, não foram encontradas muitas publicações em português, devido a isso foram utilizados os termos em inglês, e para que o objetivo fosse atingido nas duas pesquisas dos termos encontra-se a palavra enxuta. Ao verificar as pesquisas na base de dados, foram encontradas publicações em comum, sendo excluídas para que tivesse uma maior exatidão nos resultados, isso ocorre devido ao fato de que a Construção enxuta é relacionada com as palavras produção enxuta e construção.

O software utilizado VOSviewer é uma ferramenta de simples manipulação, que apresenta resultados significativos, assim como outros softwares para análise bibliométrica. O software não permite muitos tipos de configurações para a manipulação dos dados, entretanto, seus resultando permitem uma visualização efetiva dos dados através do método escolhido.

A Tabela 3, a seguir, mostra os dados utilizados para que a pesquisa entre os dois termos fosse unificada, pois o foco foi encontrar as técnicas e ferramentas utilizadas no planejamento em empresas de construção civil. A Tabela 3 também apresenta a quantidade de artigos encontrados, os artigos a serem utilizados, as palavras-chave repetidas, o mínimo de ocorrências buscadas e as palavras-chave encontradas utilizando o mínimo definido. A quantidade mínima de ocorrência foi definida após testes no software analisando as palavras-chave e os clusters, sempre foi definido conforme aparecem mais palavras relacionadas a planejamento. Sabendo que quanto mais artigos, maior pode ser o mínimo de ocorrência. 
Tabela 3 - Dados considerados durante a análise bibliométrica para cada termo.

\begin{tabular}{cccccc} 
Termo pesquisado & $\begin{array}{c}\text { Artigos } \\
\text { encontrados }\end{array}$ & $\begin{array}{c}\text { Artigos } \\
\text { utilizados }\end{array}$ & $\begin{array}{c}\text { Palavras- } \\
\text { chave } \\
\text { repetidas }\end{array}$ & $\begin{array}{c}\text { Mínimo de } \\
\text { ocorrência } \\
\text { definido }\end{array}$ & $\begin{array}{c}\text { Palavras- } \\
\text { chave } \\
\text { definidas }\end{array}$ \\
\hline $\begin{array}{c}\text { Construção enxuta } \\
\text { (lean construction) }\end{array}$ & 252 & 252 & 860 & 10 & 17 \\
$\begin{array}{c}\text { Produção enxuta e } \\
\text { Construção (lean } \\
\text { production and } \\
\text { construction) }\end{array}$ & 197 & 105 & 544 & 6 & 19 \\
\hline Fonte: Autores & & & & & \\
\hline
\end{tabular}

Fonte: Autores

Ao analisar a Tabela 3, verificamos que o segundo termo pesquisado, "Lean production" and "Construction", Produção enxuta e Construção, foram utilizados na análise 105 artigos, destes artigos são extraídas 544 palavras-chave repetidas, porém definimos o mínimo de ocorrência em 6 , onde 19 palavras-chave são repetidas 6 vezes.

Desejou-se unificar as informações encontradas na pesquisa, então a seguir, na Tabela 4, podemos ver que unimos as palavras-chave das duas buscas de dados, para encontrar as melhores técnicas e ferramentas de planejamento, sendo assim, estudaremos os 357 artigos.

Ao analisar os 357 artigos, unindo as palavras-chave encontradas, considerando o cluster no qual a palavra-chave pertence, sendo excluídas destas palavras relacionadas a "Lean Construction", "Lean Production", "Construction" e "Lean", com a finalidade de refinar a identificação das técnicas e ferramentas de planejamento mais utilizadas. Foram excluídas as palavras-chave que não tem relação alguma com planejamento, o que já poderia ter sido excluído da pesquisa na interpretação dos resultados, não foram excluídas anteriormente, por ser considerada a análise da força de ligação entre as palavras. 
Tabela 4 - Técnicas e ferramentas de planejamento identificadas na pesquisa

\begin{tabular}{|c|c|c|c|c|c|c|}
\hline \multicolumn{2}{|c|}{ Cluster } & \multicolumn{2}{|c|}{ Palavra-chave } & \multicolumn{3}{|c|}{ Ocorrência } \\
\hline $\begin{array}{c}\text { Construção } \\
\text { Enxuta }\end{array}$ & $\begin{array}{c}\text { Produção } \\
\text { Enxuta e } \\
\text { Construção }\end{array}$ & Português & Inglês & $\begin{array}{l}\text { Construção } \\
\text { Enxuta }\end{array}$ & $\begin{array}{l}\text { Produção } \\
\text { Enxuta e } \\
\text { Construção }\end{array}$ & Total \\
\hline 2 & 1 & Gestão & Management & 33 & 21 & 54 \\
\hline 1 & - & $\begin{array}{l}\text { Gestão da } \\
\text { construção }\end{array}$ & $\begin{array}{l}\text { Construction } \\
\text { management }\end{array}$ & 19 & & 19 \\
\hline 2 & - & $\begin{array}{l}\text { Last planner } \\
\text { system (LPS) }\end{array}$ & & 15 & & 15 \\
\hline 1 & - & $\begin{array}{c}\text { Gerenciamento } \\
\text { de projeto } \\
\text { Building }\end{array}$ & $\begin{array}{c}\text { Project } \\
\text { management }\end{array}$ & 11 & & 11 \\
\hline 2 & - & $\begin{array}{c}\text { Information } \\
\text { Modeling (BIM) }\end{array}$ & & 11 & & 11 \\
\hline- & 3 & $\begin{array}{l}\text { Cadeia de } \\
\text { suprimentos }\end{array}$ & Supply chain & & 10 & 10 \\
\hline- & 3 & $\begin{array}{l}\text { Mapeamento } \\
\text { do Fluxo de } \\
\text { Valor }\end{array}$ & $\begin{array}{l}\text { Value stream } \\
\text { mapping }\end{array}$ & & 6 & 6 \\
\hline
\end{tabular}

Fonte: Autores

Em relação aos resultados da visualização de sobreposição obtida pelo software VOSviewer, constatamos que entre os anos de 2014 a 2016, foram de maior evidência dos termos pesquisados, "Lean Construction", e "Lean Production" and "Construction", lembrando que o período analisado era de 2008 a 2018. Quase não se encontram publicações anteriores a 2014, talvez por ser um tema recente. "Lean Construction" foi um termo que surgiu em 1992, porém tem sido mais aplicado nos dias atuais, devido a competitividade entre as empresas da construção, que buscam obter lucros, diminuindo os desperdícios, então é um assunto que está em crescimento. A Tabela 5 e a Figura 8 apresentam o ano médio de publicações das palavras-chave selecionadas. 
Tabela 5 - Ano médio de publicações das palavras-chave selecionadas

Palavras-chave

Ano médio de publicação

\begin{tabular}{|c|c|c|c|c|}
\hline Referência & Português & Inglês & $\begin{array}{c}\text { Construção } \\
\text { Enxuta }\end{array}$ & $\begin{array}{c}\text { Produção. } \\
\text { Enxuta e } \\
\text { construção }\end{array}$ \\
\hline 1 & Gestão & \multirow{3}{*}{$\begin{array}{l}\text { Management } \\
\text { Construction } \\
\text { management }\end{array}$} & 2015,55 & 2013,76 \\
\hline 2 & Gestão da construção & & 2014,58 & \\
\hline 3 & Last planner system (LPS) & & 2014,27 & \\
\hline 4 & Gerenciamento de projeto & \multirow[t]{2}{*}{ Project management } & 2013,73 & \\
\hline 5 & $\begin{array}{l}\text { Building Information Modeling } \\
\text { (BIM) }\end{array}$ & & 2016,91 & \\
\hline 6 & Cadeia de suprimentos & \multirow{2}{*}{$\begin{array}{l}\text { Supply chain } \\
\text { Value stream } \\
\text { mapping }\end{array}$} & & 2015,50 \\
\hline 7 & $\begin{array}{l}\text { Mapeamento do Fluxo de } \\
\text { Valor }\end{array}$ & & & 2016,00 \\
\hline
\end{tabular}

Fonte: Autores

Figura 8 - Gráfico do ano médio das palavras-chave selecionadas

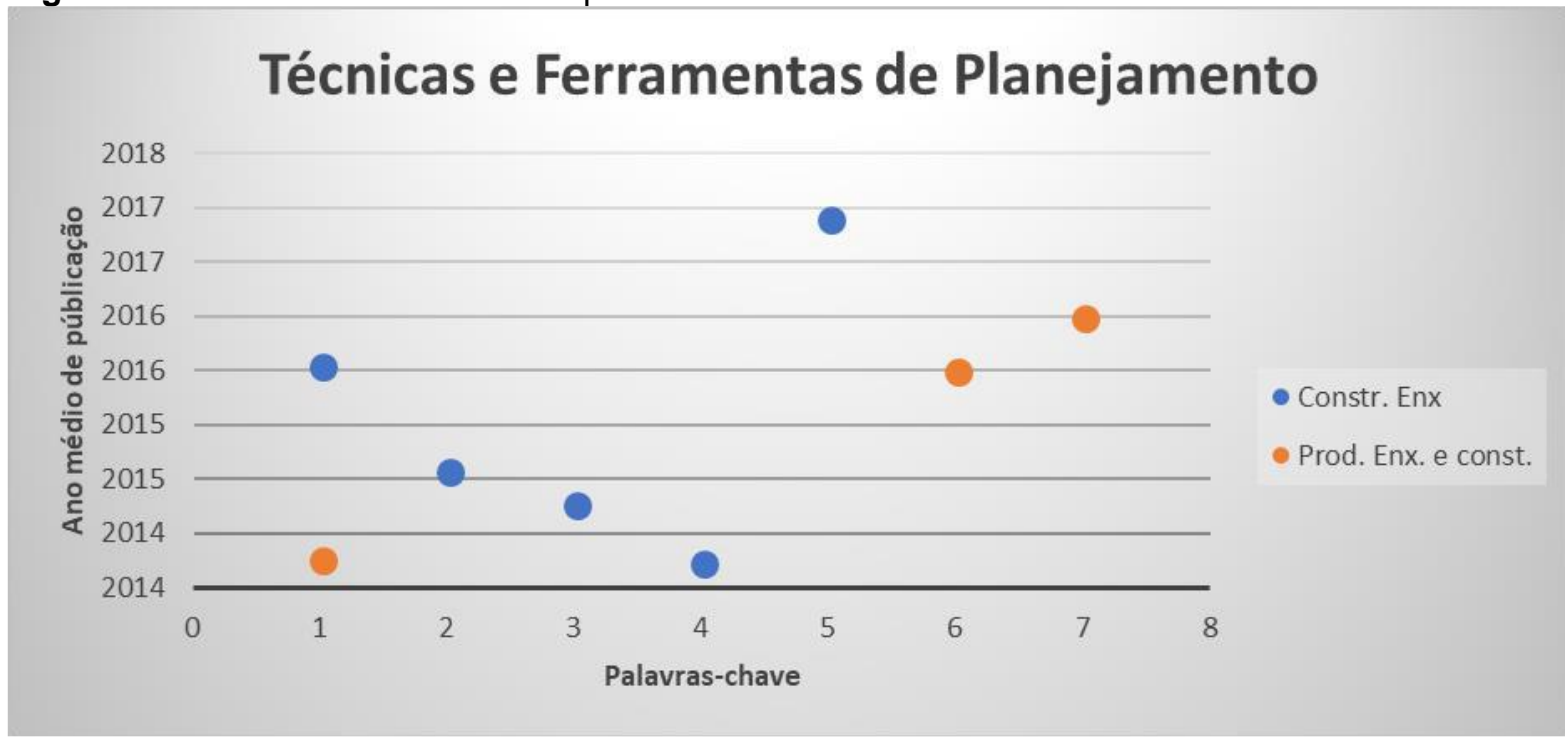

Fonte: Autores através do software VOSviewer

\section{CONCLUSÕES}

Esse trabalho teve como objetivo realizar uma análise bibliométrica sobre a Construção Enxuta. Buscou-se igualmente pesquisar quais as técnicas e ferramentas de planejamento utilizadas em empresas de construção civil. Foram analisadas as publicações dos últimos 10 anos, de 2008 a 2018. Foi apresentada uma revisão bibliográfica dos conceitos de Construção Enxuta, de Produção Enxuta e de Planejamento e Controle da Produção, para ajudar na compreensão das técnicas e ferramentas a serem pesquisadas. 
A metodologia proposta para a realização da Análise Bibliométrica foi dividida em: projeto de pesquisa, seleção de dados e a análise bibliométrica. A análise bibliométrica foi do tipo análise de co-ocorrência de palavras para as duas buscas de dados, os termos foram: "Lean Construction", e "Lean Production" and "Construction". Para essa busca utilizamos a base de dados Web of Science (WOS), onde pesquisa os termos nas publicações dentro de cada área de conhecimento, por isso os dados encontrados são poucos em português.

Após obter os arquivos gerados pelabase de dados WOS, os mesmos são exportados para o software VOSviewer para realizar a análise bibliométrica, gerando três tipos de visualizações das palavras-chave em relação aos termos da base de dados.

As visualizações foram realizadas unindo as duas pesquisas dos termos, identificando as técnicas e as ferramentas relacionadas a planejamento mais utilizadas, que são: Gestão, Gestão da Construção, Last Planner System (LPS), Gerenciamento de Projeto, Building Information Modeling (BIM), Cadeia de Suprimentos e Mapeamento do Fluxo de Valor (MFV). Esse resultado pode ajudar a profissionais conhecerem as principais referências sobre o tema, dando assim diretrizes para a aplicação da Construção Enxuta em sua empresa.

A análise bibliométrica mostra também o ano médio de publicação de cada palavra-chave, mostrando que as pesquisas são recentes, nas duas pesquisas as publicações em torno da Construção Enxuta são entre 2014 e 2016. É possível identificar um crescimento considerável de publicações, apresentando um avanço constante no número de publicações, o que indica que a área está se consolidando e aumentando em pesquisas científicas. Ainda assim, o crescimento pode ser considerado pouco comparado com o crescimento do setor de construção civil.

Por fim, uma análise bibliométrica foi realizada referente às técnicas e ferramentas de planejamento, baseadas na construção enxuta, para empresas de construção civil. Esta pesquisa pode ser relevante e útil para encontrar publicações científicas na área de construção civil, usando os dados como ferramenta para o planejamento melhorar o desempenho da produtividade, melhorar a qualidade e reduzir a variabilidade nos projetos de construção civil, trazendo melhoria contínua nos processos, oferecendo qualidade e lucros na obra. 
Para trabalhos futuros há a possibilidade de ampliação dos artigos publicados, sem limitação dos mais citados, para que possamos abranger um maior número de registros para posterior análise bibliométrica no software VOSviewer. Sugere-se igualmente a utilização de outras bases de dados bilbiográficos como também outros softwares de análise bibliométrica. Outros formatos de textos também poderão ser considerados durante a pesquisa para que diferentes tipos de materiais sejam contemplados durante a pesquisa.

\section{REFERÊNCIAS}

ALVIM, C. M. Aplicação do planejamento e controle da produção na construção civil estudo de caso na Ribeiro Alvim Engenharia Ltda. 2013. 77f. TCC (Graduação em Engenharia de Produção) - Universidade Federal de Juiz de Fora, Juiz de Fora, 2013.

ARAÚJO, C. A. Bibliometria: evolução histórica e questões atuais. Revista em Questão, v. 12, n. 1, p.11-32, jan./jun. 2006.

ARAÚJO, N. M. C.; MEIRA, G. R. O papel do planejamento, interligado a um controle gerencial, nas pequenas empresas de construção civil. In: ENCONTRO NACIONAL DE ENGENHARIA DE PRODUÇÃO, 17., 1997. Gramado, 1997. [Anais...]. Gramado, 1997. Disponível em: http://www.abepro.org.br/biblioteca/enegep1997 t3103.pdf. Acesso em: 30 set. 2017.

BALLARD, G.; HOWELL, G. An Update on Last Planner. In: ANNUAL CONFERENCE OF LEAN CONSTRUCTION, 12., 2004. [Proceedings...]. Elsinore, 2004.

BERNARDES, M. M. e S. Planejamento e controle da produção para empresas de construção civil. Rio de Janeiro: LTC, 2003, 280 p.

BERTELSEN, S.; KOSKELA, L. Construction beyond Lean: A New Understanding of Construction Management. Proceedings... In: 12th Annual Conference of Lean Construction. IGLC. Elsinore, 2004.

CÂNDIDO, L. F.; CARNEIRO, J. Q.; HEINECK, L. F. M. Análise da Aplicação da Técnica de Gerenciamento de Valor Agregado (EVM) em Projetos de Construção Enxuta. Revista Produção Online, Florianópolis, SC, v. 16, n. 3, p. 947-965, jul./set. 2016. https://doi.org/10.14488/1676-1901.v16i3.2227

CHEN, C.; IBEKWE-SANJUAN, F.; HOU, J. The structure and dynamics of co-citation clusters: a multiple perspective co-citation analysis. Journal of American Society for Information Science and Technology, 33 p., 2011. Disponível em: https://hal.archivesouvertes.fr/hal-00638091/document. Acesso em: 2 jun. 2018.

CORRÊA, H.L.; GIANESI, I.G.N.; CAON, M. Planejamento, programação e controle da produção. São Paulo: Atlas, 1996. 
COSTA, J. D. Aplicação na construção civil de técnicas e ferramentas de planejamento e controle, baseados no conceito da construção enxuta. 2016. 68f. Dissertação

(Graduação em Engenharia Civil) - Universidade Federal do Rio de Janeiro, Rio de Janeiro, 2016.

GAITHER, N.; FRAIZER, G. Administração da produção e operações. 8. ed., São Paulo: Pioneira Thomson Learning, 2001.

GEORGE, M. L. Lean seis sigma para serviços: como utilizar velocidade lean e qualidade seis sigma para melhorar serviços e transações, 2004

GREEF, A. C.; FREITAS, M. do C. D.; ROMAEL, F. B. Lean office: operação, gerenciamento e tecnologia. São Paulo: Atlas, 2012.

ISATTO, E. L.; FORMOSO, C. T.; CESARE, C. M.; HIROTA, E. H.; ALVES, T. C. L. Lean Construction: diretrizes e ferramentas para o controle de perdas na construção civil. Porto Alegre: SEBRAE/RS, 2000, v. 5, 11 p.

IZIDORO, F. S. Aplicação do planejamento e controle da produção na indústria da construção civil baseado nos princípios da produção enxuta. 2014. 99f. Dissertação (Graduação em Engenharia de Produção) - Instituto Federal de Educação, Ciência e Tecnologia de Minas Gerais, Governador Valadares, 2014.

KOSKELA, L. Application of the new production to construction. Finland: Center for Integrated Facility Engineering, 1992. Disponível em:

http://www.leanconstruction.org/media/docs/Koskela-TR72.pdf. Acesso em: 7 out. 2017.

KOSKELA, L. Lean Production in Construction. Proceeding In: CONFERENCE OF THE INTERNATIONAL GROUP FOR LEAN CONSTRUCTION, Santiago, Chile, 1994.

KOSKELA, L. An exploration towards a production theory and its application to construction. 2000. 298 p. Thesis (Engineering Doctoral Thesis) - Helsinki University of Technology, Espoo, Finland, 2000.

KOTLER, P. Administração de marketing. São Paulo: Prentice Hall, 2000, 10 ed., 764 p.

LEITE, M. O.; PINHO, I. B.; PEREIRA, P. E.; HEINECK, L. F. M.; ROCHA, F. E. M. Aplicação do sistema kanban no transporte de materiais na construção civil. In: ENCONTRO NACIONAL DE ENGENHARIA DE PRODUÇÃO, 24., 2004. [Anais...]. Florianópolis, SC, Brasil, 03 a 05 de nov. de 2004. https://doi.org/10.14488/1676-1901.v4i4.1847

MARIZ, R. N.; PICCHI, F. A. Aplicação de célula de produção no serviço de execução de fachada: um estudo de caso na construção civil. Revista Produção Online, Florianópolis, SC, v.14, n. 2, p. 703-719, abr./jun. 2014. https://doi.org/10.14488/1676-1901.v14i2.1499

MARTINS, P. G.; LAUGENI, F.P. Administração da produção. 2. ed. Saraiva, São Paulo, 2005.

MATTOS, A. D. Planejamento e controle de obras. São Paulo: Pini, 1 ed., 2010.

MORAES, R. O. Gestão Estratégica de Custos: Investigação da Produção Científica no período de 2008 a 2012. In: CONGRESSO BRASILEIRO DE CUSTOS, 20., 2013, 
Uberlândia. [Anais eletrônicos...]. Uberlândia, 2013. Disponível em:

https://anaiscbc.emnuvens.com.br/anais/article/download/131/131. Acesso em: 26 maio 2018.

MORETTI, S. L A.; CAMPANÁRIO, M. A. A produção intelectual brasileira em responsabilidade social empresarial - RSE sob a ótica da bibliometria. 2009. Revista de Administração Contemporânea, Curitiba, v. 13, Ed. especial, art. 4, p. 68-86, jun. 2009. https://doi.org/10.1590/S1415-65552009000500006

OHNO, T. O Sistema toyota de produção: além da produção em larga escala. Porto Alegre: Bookman, 1997, 150 p.

PERETTI, L. C.; FARIA, A. C.; SANTOS, I. C.; Aplicação dos Princípios da Construção Enxuta em construtoras verticais: estudos de Casos múltiplos na Região Metropolitana de São Paulo. In: ENANPAD, 37., 2013. [Anais...]. 2013.

PICCHI, F. A. Oportunidades da aplicação do lean thinking na construção. Revista Ambiente Construído, Porto Alegre: v. 3, n. 1, p. 7-23, 2003.

PICCIRILLO, I. N.; SILVA, B. B.; PAKES, P. R.; MANO, A. P. Análise bibliométrica lean construction. In: ENCONTRO NACIONAL DE ENGENHARIA DE PRODUÇÃO, 36., 2016, João Pessoa. [Anais eletrônicos....] João Pessoa, 2016. Disponível em:

http://www.abepro.org.br/biblioteca/TN STP 227329 29846.pdf. Acesso em: 27 maio 2018.

PIRES, D. L. P. Aplicação de técnicas de controle e planejamento em edificações. 2014. 59f. Dissertação (Especialização em Construção Civil) - Universidade Federal de Minas Gerais, Belo Horizonte, 2014.

RAGO, S. F. Atualidades na gestão de manufatura. São Paulo: IMAM, p. 21-23, 2003.

TUBINO, D. F. Planejamento e controle da produção: teoria e prática. São Paulo: Atlas, 2007, 304 p.

WOMACK, J. P.; JONES, D. T. A mentalidade enxuta nas empresas: elimine o desperdício e crie riqueza. 11. ed. Rio de janeiro: Campus, 1998. 428 p.

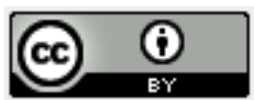

Artigo recebido em: 07/01/2019 e aceito para publicação em: 20/09/2020 DOI: http://dx.doi.org/10.14488/1676-1901.v20i3.3524 